\title{
The effects of exercise training and caloric restriction on the cardiac oxytocin natriuretic peptide system in the diabetic mouse
}

\author{
This article was published in the following Dove Press journal: \\ Diabetes, Metabolic Syndrome and Obesity:Targets and Therapy \\ II January 2017 \\ Number of times this article has been viewed
}

\author{
Tom L Broderick' \\ Marek Jankowski² \\ Jolanta Gutkowska² \\ 'Department of Physiology, \\ Laboratory of Diabetes and \\ Exercise Metabolism, Midwestern \\ University, Glendale, AZ, USA; \\ ${ }^{2}$ Department of Medicine, Laboratory \\ of Cardiovascular Biochemistry, \\ Centre Hospitalier de I'Université \\ de Montréal-Hôtel-Dieu, Montréal, \\ QC, Canada
}

Background: Regular exercise training (ET) and caloric restriction (CR) are the frontline strategies in the treatment of type 2 diabetes mellitus with the aim at reducing cardiometabolic risk. ET and CR improve body weight and glycemic control, and experimental studies indicate that these paradigms afford cardioprotection. In this study, the effects of combined ET and CR on the cardioprotective oxytocin (OT)-natriuretic peptide (NP) system were determined in the $\mathrm{db} / \mathrm{db}$ mouse, a model of type 2 diabetes associated with insulin resistance, hyperglycemia, and obesity. Methods: Five-week-old male db/db mice were assigned to the following groups: sedentary, $\mathrm{ET}$, and ET $+\mathrm{CR}$. Nonobese heterozygote littermates served as controls. ET was performed on a treadmill at moderate intensity, and CR was induced by reducing food intake by $30 \%$ of that consumed by sedentary $\mathrm{db} / \mathrm{db}$ mice for a period of 8 weeks.

Results: After 8 weeks, only ET + CR, but not ET, slightly improved body weight compared to sedentary $\mathrm{db} / \mathrm{db}$ mice. Regardless of the treatment, $\mathrm{db} / \mathrm{db}$ mice remained hyperglycemic. Hearts from $\mathrm{db} / \mathrm{db}$ mice demonstrated reduced expression of genes linked to the cardiac OT-NP system. In fact, compared to control mice, mRNA expression of GATA binding protein 4 (GATA4), OT receptor, OT, brain NP, NP receptor type C, and endothelial nitric oxide synthase (eNOS) was decreased in hearts from sedentary $\mathrm{db} / \mathrm{db}$ mice. Both ET alone and ET $+\mathrm{CR}$ increased the mRNA expression of GATA4 compared to sedentary $\mathrm{db} / \mathrm{db}$ mice. Only ET combined with CR produced increased eNOS mRNA and protein expression.

Conclusion: Our data indicate that enhancement of eNOS by combined ET and CR may improve coronary endothelial vasodilator dysfunction in type 2 diabetes but did not prevent the downregulation of cardiac expression in the OT-NP system, possibly resulting from the sustained hyperglycemia and obesity in diabetic mice.

Keywords: running, diabetes, GATA4, oxytocin, natriuretic peptides, db/db

\section{Introduction}

The association between a sedentary lifestyle and the risk of developing cardiovascular and metabolic diseases is well established. In recent decades, the dramatic rise in sedentary lifestyle behavior has resulted in an unprecedented increase in the prevalence of obesity, type 2 diabetes, and vascular diseases. ${ }^{1-3}$ Type 2 diabetes is a chronic metabolic disorder and, with its high prevalence worldwide, is considered as one of the leading health threats in developed nations. Decreasing this unfavorable association between a sedentary lifestyle and cardiometabolic outcome can be accomplished by effective nonpharmacological approaches, such as limiting the caloric intake and
Correspondence: Tom L Broderick Department of Physiology, Laboratory of Diabetes and Exercise Metabolism, Midwestern University, 19555 North 59th Avenue, Glendale, AZ 85308, USA Tel +l 6235723664

Fax +l 6235723673

Email tbrode@midwestern.edu 
increasing the level of physical activity. ${ }^{4}$ Regular exercise is warranted for the treatment of type 2 diabetes for its positive outcome on cardiovascular risk factors. Epidemiological studies unequivocally indicate that exercise training (ET) is an effective method in improving blood glucose regulation, insulin resistance, blood lipids, and blood pressure. ${ }^{5-7}$ The limited exercise capacity and impaired energy metabolism can also be improved, delaying the onset and progression of cardiovascular disease in patients with type 2 diabetes. ${ }^{8,9}$ In addition to exercise, a great body of evidence has shown that limiting food intake is an effective frontline strategy to reduce cardiometabolic risk and disorders. ${ }^{10,11}$ Reports have indicated that caloric restriction (CR) attenuates the development of cardiomyopathy and decline in heart function normally associated with aging. ${ }^{12}$ Moderate CR decreases visceral fat and blood pressure and improves the lipid profile, glucose uptake, and insulin sensitivity, and hearts from CR rodents show an improved ischemic tolerance. ${ }^{13-16}$ Furthermore, CR preserves pancreatic mass and function by suppressing apoptosis in the $\mathrm{db} / \mathrm{db}$ mouse, ${ }^{17}$ attenuates the development of hepatic steatosis in the $\mathrm{db} / \mathrm{db}$ mice, ${ }^{18}$ and decreases adiposity in the genetically hyperphagic OLEFT model of type 2 diabetes. ${ }^{19}$ Taken together, it is clear that the benefits of ET and CR share a common favorable outcome on cardiovascular and metabolic health. ${ }^{20}$

To date, few studies have investigated the effects of combined ET and CR on cardiometabolic protection in type 2 diabetes. Recent work has demonstrated that the obesity and insulin resistance induced by a high-fat diet (diet-induced obesity [DIO]) in mice were reversed with exercise and CR. ${ }^{21}$ Using the same model of obesity, Cui et $\mathrm{al}^{22}$ reported that $\mathrm{CR}$ and treadmill running improved common cardiovascular risk factors, decreased plasma leptin, increased plasma adiponectin, and activated autophagyrelated pathways in the cardiac muscle. Decreasing the caloric intake and increasing the energy expenditure by voluntary exercise in the hypoleptinemic ob/ob mouse reduced fasting hyperglycemia and hyperglucagonemia but failed to reduce plasma insulin levels. ${ }^{23,24}$ In the $\mathrm{db} / \mathrm{db}$ mouse, a model characterized by insulin resistance, hyperglycemia, and hyperleptinemia as a result of a mutation that inactivates the leptin receptor, combining exercise and dietary energy restriction improved fasting blood glucose. ${ }^{25}$ The effects of this combined intervention approach on metabolic control using the $\mathrm{db} / \mathrm{db}$ mouse are unclear. The fact is that, overall, there is limited literature examining the effects of this combined nonpharmacological approach in the $\mathrm{db} / \mathrm{db}$ mouse, particularly for cardioprotective genes.
Oxytocin (OT) is a cardiovascular hormone with robust cardioprotective effects. In heart, OT exerts direct cardioprotection through the OT receptor (OTR), or indirectly via the stimulation of natriuretic peptides (NPs; atrial NP [ANP], brain NP [BNP], and C-type) and nitric oxide (NO) synthesis. ${ }^{26,27}$ This functional OT-NP-NO system is downregulated in hearts from $\mathrm{db} / \mathrm{db}$ mice. ${ }^{28,29}$ The contribution of this system to the development of diabetic cardiomyopathy is indicated by the fact that chronic administration of OT and BNP prevented cardiac dysfunction and heart remodeling naturally developing in the $\mathrm{db} / \mathrm{db}$ mice. ${ }^{30,31}$ We have demonstrated that ET improves expression of the OT-NP system in ovariectomized rats $^{32}$ but fails to reverse most components of this cardioprotective system in the diabetic mouse. ${ }^{28,33}$ It is unknown to what extent the development of cardiomyopathy in exercised $\mathrm{db} / \mathrm{db}$ mice is associated with binge eating that is common in the diabetic $\mathrm{db} / \mathrm{db}$ mouse. ${ }^{34}$ Some light on this problem may be obtained by limiting the excess of food intake during ET. In fact, while cardiac levels of the OT, ANP, and BNP remained low, ET only partially reversed the defect in NO synthesis, ${ }^{28,33}$ while other studies indicate an improved lipid profile and vascular function. ${ }^{35,36}$ Considering the supportive role of reduced dietary intake in metabolic control in diabetes, the present study examined the effects of combined ET and CR on the OT-NP system in the heart from the $\mathrm{db} / \mathrm{db}$ mouse.

\section{Methods}

\section{Mouse model of diabetes}

This study was approved by the Midwestern University Research and Animal Care Committee. All animals used in this study were cared in accordance with the recommendations in the Guide for the Care and Use of Laboratory Animals, National Institute of Health, publication number 85-23, 1986. Five-week-old male db/db mice (C57BL/6J background strain; B6.V-Lep ${ }^{\mathrm{db}}$ strain) were obtained from Jackson Laboratory (Bar Harbor, ME, USA). The strain displays both the metabolic alterations and cardiac dysfunction seen in diabetes and obesity. ${ }^{37}$ The onset of diabetes in this strain is gradual and characterized by hyperphagia with a subsequent development of hyperglycemia as a result of two mutant copies of the leptin receptor gene. The lean littermate, which is characterized by only one mutation of the leptin gene, was used as control.

\section{Experimental groups and ET protocol}

Diabetic $\mathrm{db} / \mathrm{db}$ mice were assigned to the following three groups: sedentary, diabetic runners (ET), and diabetic runners with CR $(\mathrm{ET}+\mathrm{CR})$. Exercise was performed on a treadmill 
(Exer 3/6 treadmill; Columbus Instruments, Columbus, $\mathrm{OH}$, USA) at moderate intensity of 5 days/week for 8 weeks, as previously reported. ${ }^{28}$ The training regimen consisted of the following 3-week graded increase in exercise duration and intensity: week 1, 10 minutes at $10 \mathrm{~m} /$ minute; week 2, $20 \mathrm{~min}$ utes at $10 \mathrm{~m} /$ minute; week 3, 30 minutes at $12 \mathrm{~m} /$ minute. From weeks 4 to 8 , the intensity was increased 30 minutes at $15 \mathrm{~m} /$ minute, corresponding to an estimated submaximal $\mathrm{VO}_{2}$ of $\sim 50 \mathrm{~mL} / \mathrm{kg} /$ minute. ${ }^{38}$ In mice assigned to the ET + CR group, the amount of food provided on a daily basis was reduced by $30 \%$ of the amount consumed by the sedentary group. Both ET and CR were maintained for a period of 8 weeks. Mice in groups not subjected to restricted food intake were provided with food ad libitum. All mice were maintained in a room with alternating 12 -hour light/dark cycle and kept at $22^{\circ} \mathrm{C}$.

\section{Blood glucose status of mice}

In the late morning at the end of each week, overnight fasted mice were weighed and then placed on a warm heating pad for a period of 30 minutes. Mice were then placed in a restraining chamber with the tail exposed for the collection of blood by puncturing the tip of the tail using a $23 \mathrm{G}$ needle. Blood glucose was measured collected using a commercially available kit (Wako Chemicals USA, Richmond, VA, USA). At the end of the protocol, and 48 hours after the last exercise session, overnight fasted mice were euthanized by $\mathrm{CO}_{2}$ gassing between 8 and 11 am. Hearts were rapidly removed and frozen with clamps that were precooled with light nitrogen for gene analysis.

\section{Real-time PCR}

Total RNA was extracted from freeze-clamped hearts with Trizol reagent (Invitrogen Life Technologies, Burlington, ON, USA) according to the manufacturer's protocol. To remove genomic DNA, RNA samples were incubated with $2 \mathrm{U}$ of deoxyribonuclease I (DNase I; Invitrogen Life Technologies)/ $\mu \mathrm{g}$ of RNA for 30 minutes at $37^{\circ} \mathrm{C}$. Polymerase chain reaction (PCR) was carried out in the iCycler IQ ${ }^{\mathrm{TM}}$ Real-Time PCR Detection System (Bio-Rad Laboratories, Hercules, CA, USA), using the SYBR ${ }^{\circledR}$ Green chemistry. The samples were analyzed in duplicate or triplicate. For amplification, $2 \mu \mathrm{L}$ of diluted cDNA was added to a $20 \mu \mathrm{L}$ of reaction mixture containing $1 \times$ iQ SYBR $®$ Green Supermix (Bio-Rad Laboratories) and $200 \mathrm{nM}$ forward and reverse primers. The thermal cycling program was $95^{\circ} \mathrm{C}$ for 2 minutes, followed by 40 cycles of $95^{\circ} \mathrm{C}$ for 30 seconds, $60^{\circ} \mathrm{C}$ for 30 seconds, and $72^{\circ} \mathrm{C}$ for 30 seconds. The primers were purchased from Invitrogen Life Technologies. Primer sets served to generate amplicons (Table 1). Optical data were recorded during the annealing step of each cycle. After PCR, the reaction products were melted for 1 minute at $95^{\circ} \mathrm{C}$, and the temperature was lowered to $55^{\circ} \mathrm{C}$ and then gradually increased to $95^{\circ} \mathrm{C}$ in $1.0^{\circ} \mathrm{C}$ increments, 10 seconds per increment. Optical data were collected over the duration of the temperature increments, with a dramatic drop in fluorescence occurring. This was done to ensure that only one PCR product was amplified per reaction.

The relative expression of the RT-PCR products was determined by the $\Delta \Delta \mathrm{Ct}$ method. This method calculates relative expression using the following equation: fold induction $=2^{-[\Delta \Delta \mathrm{Ct}]}$, where $\mathrm{Ct}$ is the threshold cycle, ie, the cycle number at which the sample's relative fluorescence rises above the background fluorescence, and $\Delta \Delta \mathrm{Ct}=[\mathrm{Ct}$ gene of interest (unknown sample) - Ct glyceraldehyde-3-phosphate dehydrogenase [GAPDH] (unknown sample)] - [Ct gene of interest (calibrator sample) - Ct GAPDH (calibrator sample)]. One of the control samples was chosen as the calibrator sample and tested in each PCR. Each sample was run in

Table I PCR primer sequences

\begin{tabular}{|c|c|c|c|}
\hline Gene & Sense primer $\left(5^{\prime}-3^{\prime}\right)$ & Antisense primer $\left(5^{\prime}-3^{\prime}\right)$ & Accession number \\
\hline ANP & CCTGTGTACAGTGCGGTGTC & CCTAGAAGCACTGCCGTCTC & NM_008725 \\
\hline BNP & CTGAAGGTGCTGTCCCAGAT & GTTCTTTTGTGAGGCCTTGG & NM_008726 \\
\hline GATA4 & CACTATGGGCACAGCAGCTCC & TTGGAGCTGGCCTGCGATGGTC & NM_008092 \\
\hline IRAP & CAAAGACCGAGCCAACCTGATC & GCTAAAGAGGAACAACCAGCC & NM_172827 \\
\hline NPR-A & AGTACGCCAACAACCTGGAG & AAGAGCTGTAAAGCCCACGA & NM_008727 \\
\hline$N P R-B$ & TCATGACAGCCCATGGTAAA & GGTGACAATGCAGATGTTGG & NM_173788 \\
\hline NPR-C & TGACACCATTCGGAGAATCA & TTTCACGGTCCTCAGTAGGG & NM_010933 \\
\hline eNOS & AACCAGCGTCCTGCAAAC & AACCAGCGTCCTGCAAAC & NM_0087I3 \\
\hline OT & CCTACAGCGGATCTCAGACTGA & TCAGAGCCAGTAAGCCAAGCA & NM_0II025 \\
\hline OTR & CGACTCAGGACGAAGGTGGAGGA & AAGATGACCTTCATCATTGTTC & NM_00108II47 \\
\hline Actin & ACCAACTGGGACGATATGGAGAAGA & TACGACCAGAGGCATACAGGGACAA & NM_007393 \\
\hline GAPDH & TTCACCACCATGGAGAAGGC & GGCATGGACTGTGGTCATGA & NM_008084 \\
\hline
\end{tabular}

Abbreviations: ANP, atrial natriuretic peptide; BNP, brain natriuretic peptide; eNOS, endothelial nitric oxide synthase; GAPDH, glyceraldehyde-3-phosphate dehydrogenase; GATA4, GATA binding protein 4; IRAP, insulin-regulated aminopeptidase; NPR-A, natriuretic peptide receptor type A; NPR-B, natriuretic peptide receptor type B; NPR-C, natriuretic peptide receptor type C; PCR, polymerase chain reaction; OT, oxytocin; OTR, oxytocin receptor. 
duplicate, and the mean $\mathrm{Ct}$ was taken in the $\Delta \Delta \mathrm{Ct}$ equation. GAPDH was chosen for normalization because this gene showed a consistent expression relative to other housekeeping genes among the treatment groups in our experiments.

\section{Western blot analysis}

The analysis of protein levels was performed as previously reported. ${ }^{28}$ Heart samples $(\sim 100 \mathrm{mg})$ were prepared by homogenization in modified radioimmunoprecipitation assay (RIPA) buffer $(1 \times$ phosphate-buffered saline, 1\% Igepal CA-630, $0.5 \%$ sodium deoxycholate, $0.1 \% \mathrm{SDS}, 10 \mathrm{mg} / \mathrm{mL}$ phenylmethylsulfonyl fluoride, aprotinin, $100 \mathrm{mM}$ sodium orthovanadate, and $4 \%$ protease inhibitor). After 2 hours in constant agitation at $4^{\circ} \mathrm{C}$, the samples were centrifuged at $10,000 \times g$ for 20 minutes at $4^{\circ} \mathrm{C}$. The supernatants were collected, and the protein concentration was determined by modified Bradford assay. Thirty micrograms of total protein was applied to each well of $10 \%$ sodium dodecyl sulfate-polyacrylamide gel and electrophoresed for 2 hours at $130 \mathrm{~V}$ along with a set of molecular weight markers (RPN800; Amersham Biosciences, Piscataway, NJ, USA). The resolved protein bands were then transferred onto polyvinylidene difluoride membranes (Hybond-C; Amersham Biosciences) at $20 \mathrm{~V}$ for 60 minutes at room temperature using a transfer buffer $(25 \mathrm{mmol} / \mathrm{L}$ Tris base, $192 \mathrm{mmol} / \mathrm{L}$ glycine, and 20\% methanol). The blots were blocked overnight at $4^{\circ} \mathrm{C}$ with blocking buffer $(5 \%$ nonfat milk in $10 \mathrm{mmol} / \mathrm{L}$ Tris, $\mathrm{pH} \mathrm{7.5,} 100 \mathrm{mmol} / \mathrm{L} \mathrm{NaCl}$, and $0.1 \%$ Tween 20) (Amersham Pharmacia). The membranes were then probed with specific primary antibodies for GATA binding protein 4 (GATA4) (1:500, sc-25310) and endothelial nitric oxide synthase (eNOS) (1:1000, sc-654) overnight at $4^{\circ} \mathrm{C}$. As an internal control, blots were reprobed with an anti- $\beta$-GAPDH antibody (1:20,000; G9545-200UL; SigmaAldrich, Oakville, ON, CA). Blots were then washed using tris-buffered saline washing buffer $(10 \mathrm{mmol} / \mathrm{L}$ Tris, $\mathrm{pH} 7.5$, $100 \mathrm{mmol} / \mathrm{L} \mathrm{NaCl}$, and $0.1 \%$ Tween 20 ) and incubated with horseradish peroxidase-conjugated immunoglobulin $\mathrm{G}(\mathrm{IgG})$ during 1 hour at room temperature. The blots were finally detected by chemiluminescence detection system (RPN2132; Amersham Biosciences) and visualized by exposure to Kodak X-Omat film. Densitometric measurement of the bands was performed using Photoshop 7 software.

\section{Statistics}

Data are presented as mean \pm standard error of the mean (SEM). Group mean difference was determined using analysis of variance (ANOVA analysis of variance), followed by a Tukey-Kramer comparison for post hoc analysis between treatment groups. A value of $P<0.05$ was considered significant.

\section{Results \\ Effect of ET and CR on body weight and plasma glucose}

Earlier studies have demonstrated that treadmill ET induces a modest improvement in body weight and blood glucose control in the $\mathrm{db} / \mathrm{db}$ mouse. ${ }^{28,35,36}$ Restricting the caloric intake also has beneficial effects on body weight and metabolic control. ${ }^{17-19}$ Based on these observations, we therefore examined the effects of combined treadmill training and $\mathrm{CR}$ on the diabetic state in the leptin-resistant mouse. As expected, body weight was higher in the $\mathrm{db} / \mathrm{db}$ mice than in the lean control mice (Table 2). ET alone had no effect on body weight in the $\mathrm{db} / \mathrm{db}$ mice, but when combined with $\mathrm{CR}$, a reduction was observed after 8 weeks. Plasma glucose levels were also elevated in the $\mathrm{db} / \mathrm{db}$ mice, confirming the diabetic state. However, plasma glucose levels remained elevated after ET and were not different compared with sedentary mice. ET in combination with $\mathrm{CR}$ also had no beneficial effect on plasma levels of glucose.

\section{Effect of ET and CR on cardiac GATA4 expression}

GATA4 is a transcription factor expressed in heart and known to regulate the synthesis of structural and contractile genes, as well as genes of the cardioprotective OT-NP system..$^{39,40}$ In diabetic myocardium, reduced expression of the OT-NP system is associated with apoptosis, accumulation of collagen and reduced utilization of glucose, and peripheral effects, including impaired vasodilation and diuresis. ${ }^{26,28,29,37}$ As shown in Figure 1, mRNA and protein expression of GATA4 was reduced in hearts from sedentary $\mathrm{db} / \mathrm{db}$ mice compared with control mice, confirming our earlier studies. ${ }^{28,33} \mathrm{Com}-$ pared with sedentary mice, ET of $\mathrm{db} / \mathrm{db}$ mice resulted in increased mRNA expression of GATA4. ET in combination with CR further increased mRNA expression by $25 \%$, such that the expression of GATA4 was reversed. However, GATA4 protein expression was not correspondingly increased by ET alone or in combination with CR.

Table 2 Physical characteristics of $\mathrm{db} / \mathrm{db}$ mice after treadmill running and $C R$

\begin{tabular}{|c|c|c|c|c|}
\hline Parameter & Control & Sedentary & Runners & $\begin{array}{l}\text { Runners + } \\
\text { CR }\end{array}$ \\
\hline Initial body weight (g) & $23.9 \pm 0.5$ & $34.6 \pm 0.6^{\mathrm{a}}$ & $34.1 \pm 1.3^{\mathrm{a}}$ & $34.9 \pm 0.5^{\mathrm{a}}$ \\
\hline Final body weight (g) & $26.4 \pm 0.5^{b}$ & $34.7 \pm 2.1^{\mathrm{a}}$ & $33.5 \pm 1.4^{\mathrm{a}}$ & $3 I .6 \pm I . I^{a, b}$ \\
\hline Initial glucose & $6.45 \pm 0.33$ & $18.82 \pm 1.88^{\mathrm{a}}$ & $17.84 \pm 1.59^{\mathrm{a}}$ & $14.63 \pm 1.89^{\mathrm{a}}$ \\
\hline Final glucose & $5.09 \pm 0.18^{c}$ & $19.56 \pm 1.32^{\mathrm{a}}$ & $21.68 \pm 1.66^{\mathrm{a}}$ & $22.65 \pm\left. 2.9\right|^{\mathrm{a}, \mathrm{c}}$ \\
\hline
\end{tabular}




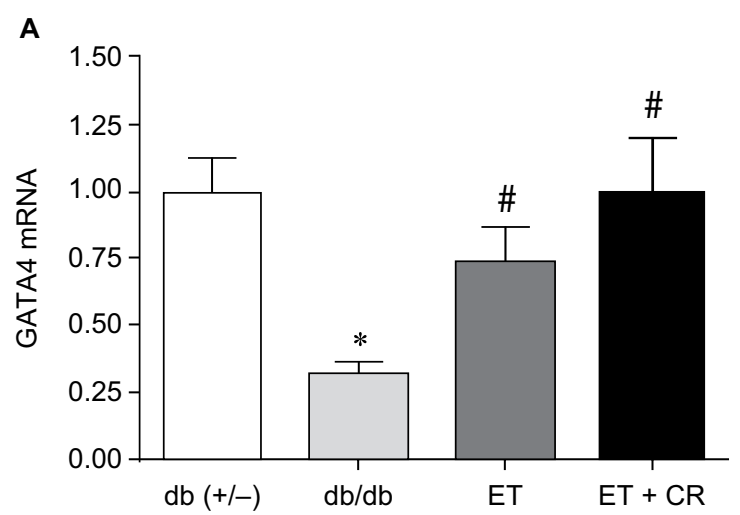

B

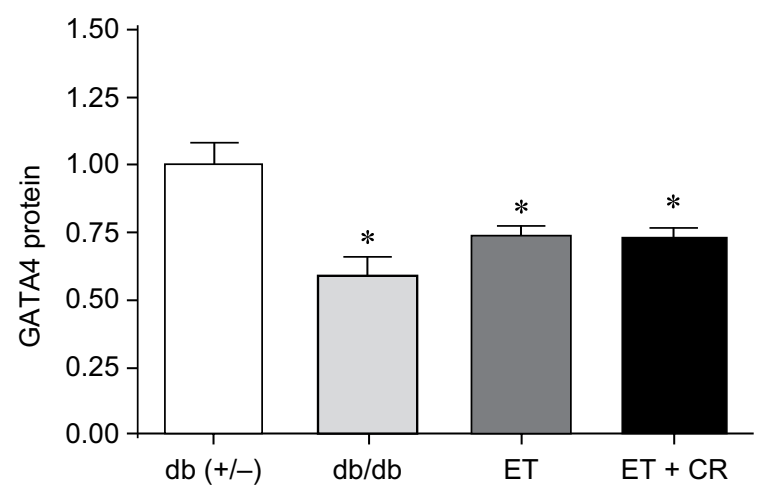

Figure I The effects of diabetes, ET, and CR on cardiac GATA4 mRNA expression (A) and protein expression (B).

Notes: Values are reported as mean \pm SEM for six mice per group. ${ }^{*}$ Compared to lean control mice. ${ }^{\sharp} P<0.05$, compared to sedentary $\mathrm{db} / \mathrm{db}$ mice.

Abbreviations: CR, caloric restriction; ET, exercise training; GATA4, GATA binding protein 4.
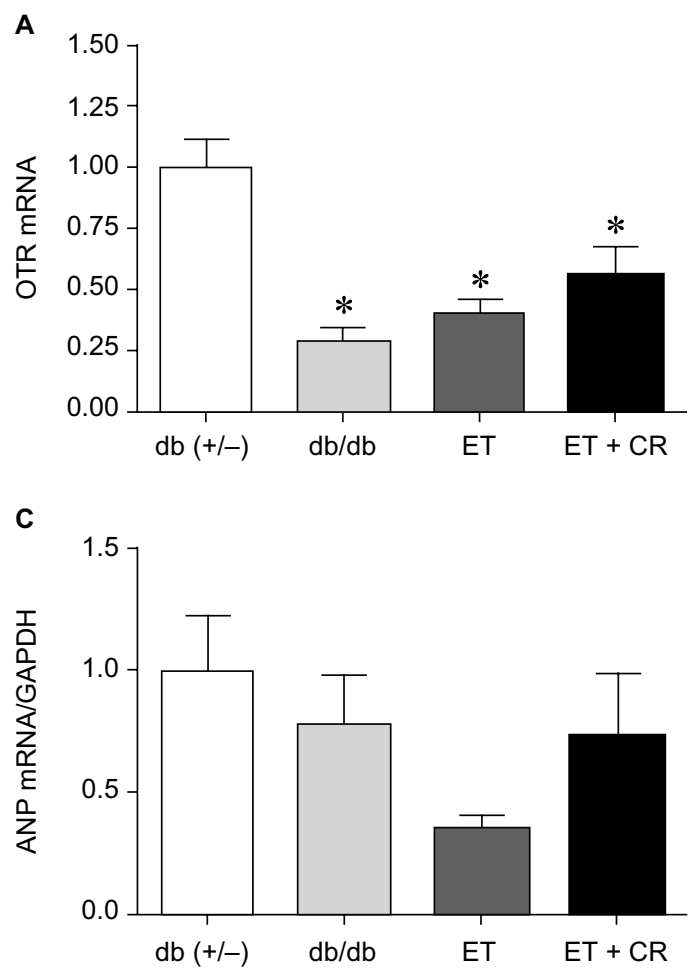

Effect of ET and CR on cardiac OTR, OT, and NP expression

OT is a cardiovascular hormone linked to the synthesis of ANP and NO, and the expression of OT is reduced under diabetic conditions. ${ }^{41}$ We next examined whether ET or combined ET and CR improved the synthesis of OT and associated NPs. Figure 2 shows that the expression of OTR was significantly reduced in hearts from sedentary $\mathrm{db} / \mathrm{db}$ mice compared with control mice. Slight increases in OTR expression following ET and ET $+\mathrm{CR}$ were observed. Indeed, compared with sedentary $\mathrm{db} / \mathrm{db}$ mice, the expression of OTR was increased by $\sim 25 \%$ with ET and by $\sim 50 \%$ with ET + CR.

Consistent with the diabetic state, the expression of OT was also significantly decreased. ${ }^{33}$ ET and ET in combination with $\mathrm{CR}$ were not effective in reversing the effect of diabetes. While no effect of diabetes on ANP expression was associated with the reduced synthesis of OT, a significant reduction in the expression of BNP in hearts from sedentary $\mathrm{db} / \mathrm{db}$ mice compared with lean control mice was observed. ET and ET with $\mathrm{CR}$ had no effect on the expression of both ANP and BNP.

\section{Effect of ET and CR on cardiac NP receptor (NPR) gene expression}

Gene expression of NPR type A (NPR-A), NPR type B

(NPR-B), and NPR type C (NPR-C) is illustrated in Figure 3.
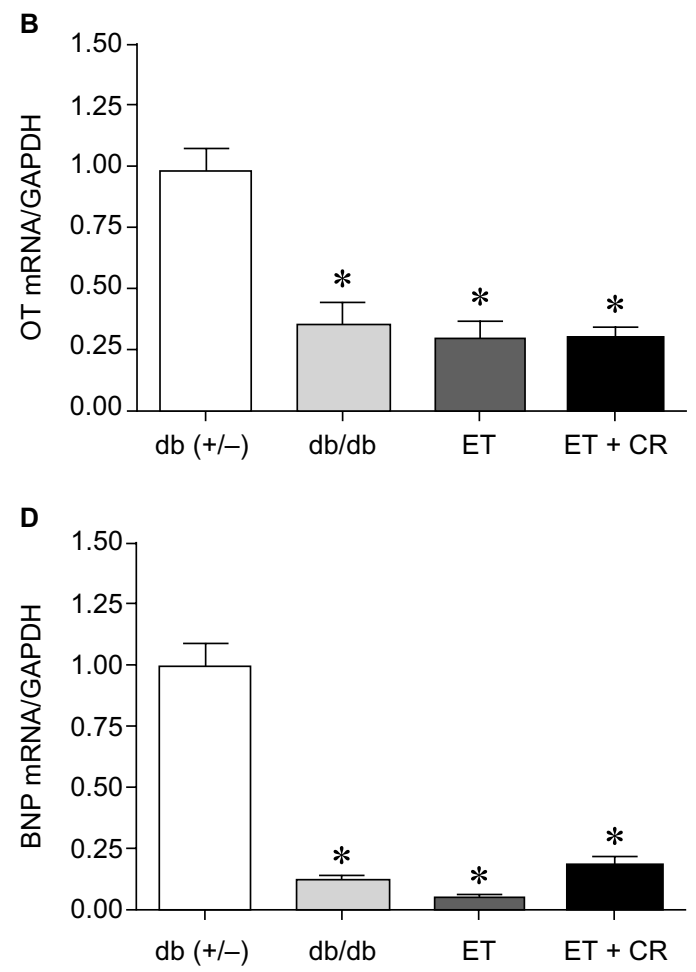

Figure 2 The effects of diabetes, ET, and CR on cardiac mRNA expression of the oxytocin receptor (A), oxytocin (B), ANP (C), and BNP (D). Notes: Values are reported as mean \pm SEM for six mice per group. *Compared to lean control mice.

Abbreviations: ANP, atrial natriuretic peptide; BNP, brain natriuretic peptide; CR, caloric restriction; ET, exercise training; GAPDH, glyceraldehyde-3-phosphate dehydrogenase; OT, oxytocin; OTR, OT receptor. 

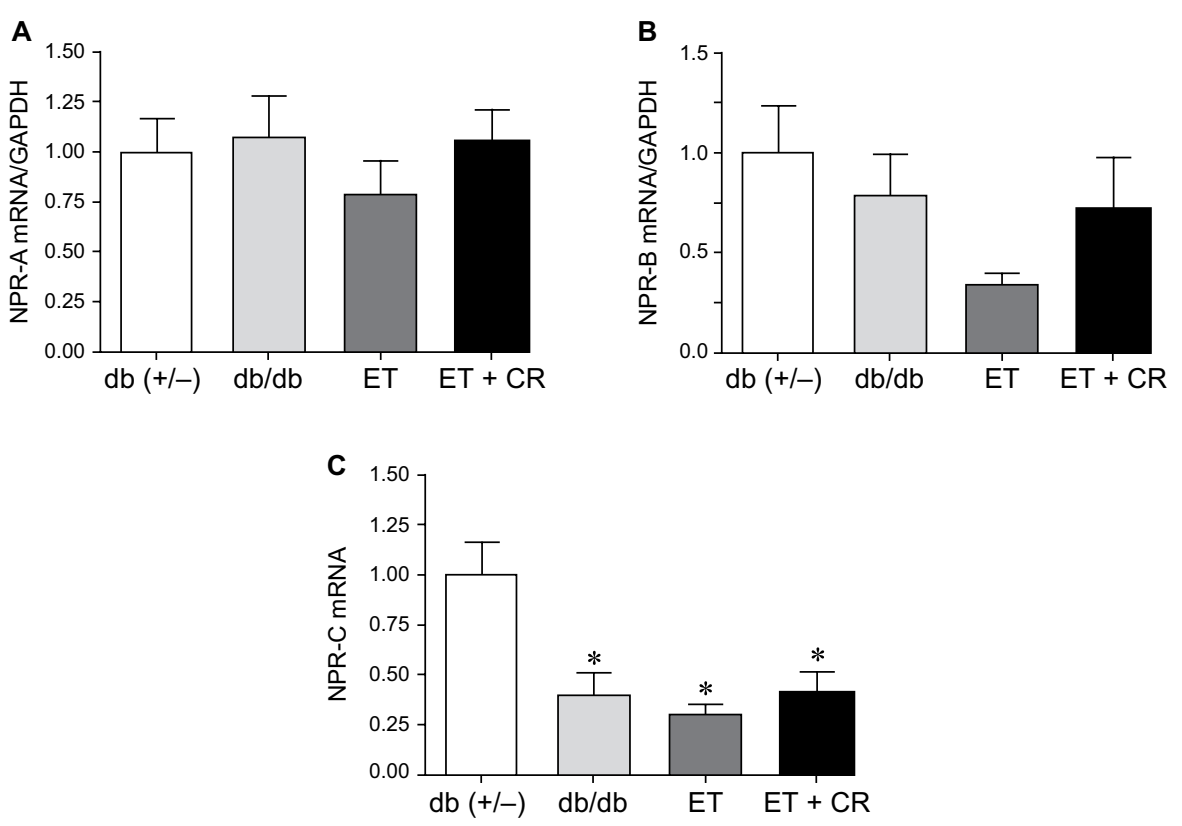

Figure 3 The effects of diabetes, ET, and CR on cardiac mRNA expression of NPR-A (A), NPR-B (B), and NPR-C (C).

Notes: Values are reported as mean \pm SEM for six mice per group. *Compared to lean sedentary control mice.

Abbreviations: ANP, atrial natriuretic peptide; CR, caloric restriction; ET, exercise training; GAPDH, glyceraldehyde-3-phosphate dehydrogenase; NPR-A, natriuretic peptide receptor type A; NPR-B, natriuretic peptide receptor type B; NPR-C, natriuretic peptide receptor type C.

Expression of NPR-A and NPR-B was not altered by diabetes, ET, or ET and CR. However, gene expression of NPR-C was decreased in hearts from sedentary $\mathrm{db} / \mathrm{db}$ mice. Similarly, a decrease in the expression of this receptor was also observed following ET and ET in combination with CR, compared with control mice.

\section{Effect of ET and CR on cardiac eNOS expression}

In addition to ANP and BNP, the expression of eNOS is also linked to the OT-NP system. ${ }^{26}$ The expression of eNOS is reduced in hearts from $\mathrm{db} / \mathrm{db}$ mice, and ET partially restores the levels of eNOS. ${ }^{28}$ Because the effects of ET in combination with $\mathrm{CR}$ on eNOS expression are unclear, this was examined. As shown in Figure 4, mRNA expression of eNOS was reduced by $\sim 40 \%$ in hearts from $\mathrm{db} / \mathrm{db}$ mice compared with control mice. This reduction was associated with a significant decrease in protein expression. While ET alone had no effect on either mRNA expression of eNOS or protein expression of eNOS, ET in combination with CR was clearly beneficial and increased both mRNA and protein expression of eNOS. In fact, eNOS protein expression was normalized by combining ET with CR. Taken together, our results indicate that ET with reduced caloric intake improves the expression of certain genes of the OT-NP system, namely the transcription factor GATA4, the OTR, and eNOS.

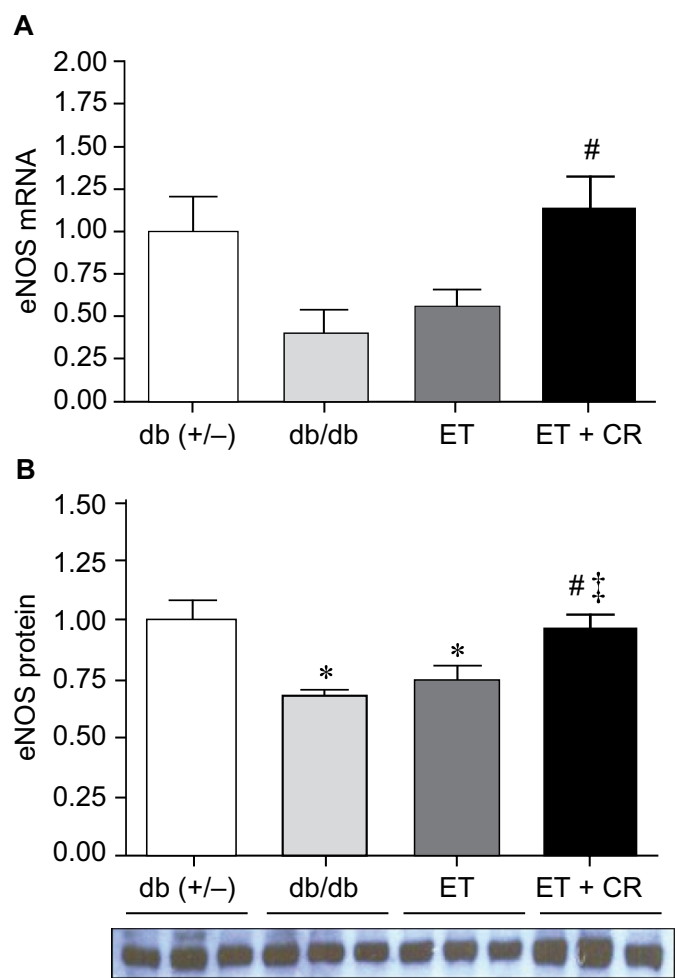

Figure 4 The effects of diabetes, ET, and CR on cardiac eNOS mRNA expression (A) and protein expression (B).

Notes: Values are reported as mean \pm SEM for six mice per group. *Compared to lean control mice. ${ }^{\#} P<0.05$, compared to sedentary $\mathrm{db} / \mathrm{db}$ mice. ${ }^{\ddagger}<0.5$, compared to exercise-trained mice.

Abbreviations: $\mathrm{CR}$, caloric restriction; eNOS, endothelial nitric oxide synthase; ET, exercise training. 


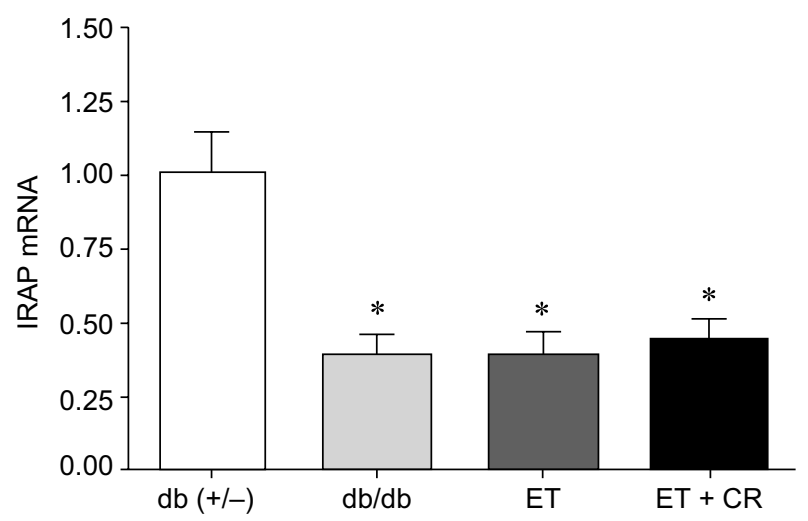

Figure 5 The effects of diabetes, ET, and CR on cardiac IRAP mRNA expression. Notes: Values are reported as mean \pm SEM for six mice per group. $*$ Compared to lean control mice.

Abbreviations: $C R$, caloric restriction; ET, exercise training; IRAP, insulinregulated aminopeptidase.

\section{Effect of ET and CR on cardiac insulin- regulated aminopeptidase (IRAP) expression}

Cardiac IRAP expression, involved in GLUT4 trafficking, ${ }^{42}$ in hearts from diabetic mice is illustrated in Figure 5. Expression of IRAP was decreased in hearts from sedentary $\mathrm{db} / \mathrm{db}$ mice, and treatment had no effect on the expression of this intracellular vesicular transporter protein.

\section{Discussion}

The nonpharmacological management of type 2 diabetes and related metabolic disorders focuses on a healthy lifestyle, which includes increasing the level of physical activity and reducing the caloric intake. This maintains better glycemic control, and a weight loss from CR improves cardiometabolic health in patients with obesity and type 2 diabetes. ${ }^{11}$ To date, most experimental studies have focused on the role of exercise or different exercise paradigms on cardioprotection in the $\mathrm{db} / \mathrm{db}$ mouse model of diabetes without concurrent restricted caloric intake. The $\mathrm{db} / \mathrm{db}$ mouse was selected because of its close representation to the phenotype observed in human diabetes and obesity. A feature of this model is hyperleptinemia from a mutation in the leptin receptor, rarely the culprit for the metabolic disturbances seen in human diabetes but nonetheless detected in diabetes. ${ }^{43}$ By including a dietary restriction component, we aimed to determine whether the defect in the OT-NP-NO system in the $\mathrm{db} / \mathrm{db}$ heart could be prevented with ET.

Our results indicate that the benefits afforded by exercise and the reduced caloric intake in the $\mathrm{db} / \mathrm{db}$ mouse were modest. A reduction in body weight was observed, but diabetic mice remained hyperglycemic after 8 weeks of ET combined with CR. In addition, with the exception of protein and gene syntheses for eNOS, ET and CR failed to significantly improve gene expression of the OTR, OT, and BNP. Gene expression of NPR-A and NPR-B was not altered by the diabetic state, ET, or ET with CR, while the expression of NPR-C was reduced under all conditions. Considering the vast body of reports indicating that combining both exercise and limited food intake is beneficial on cardiometabolic health for the treatment of diabetes, our results showing only partial reversal of the defect in the OT system in diabetic mice were clearly unexpected. The reason for this response is unclear, although evidence suggests that impaired expression of this system may be related to observation that diabetic mice remained hyperglycemic, despite the exercise combined with $\mathrm{CR} .{ }^{44}$ Indeed, evidence indicates that hyperglycemia markedly inhibits the synthesis of OT, ANP, and BNP and structural proteins by suppressing the expression of cardiac GATA4, an essential transcription factor. ${ }^{44}$ The importance of GATA4 is highlighted by the observation that low GATA4 content is further associated with an increased ischemic injury and the risk of heart failure, both of which are evident in hearts from $\mathrm{db} / \mathrm{db}$ mice. ${ }^{45}$ Although our results confirm earlier studies in the $\mathrm{db} / \mathrm{db}$ mouse, ${ }^{28}$ synthesis of the OT system is also reduced in the ob/ob mice and in hearts from mice with streptozotocin-induced type 1 diabetes or fed with high-fat diet. ${ }^{29,44,46}$ Hyperglycemia is present in all these rodent models, but it should be noted that hyperglycemia per se cannot solely account for low GATA4 expression in these models. The role of defective leptin receptor signaling, mutation of the ob gene, insulin resistance or deficiency, and calorie-rich food consumption are potential causes for the decreased expression of the OT, the OTR, and BNP. However, we have reported that hearts from $\mathrm{db} / \mathrm{db}$ mice show increased gene and protein expression of GATA4 following 8 weeks of treadmill running without concomitant changes in the expression of OT and NP synthesis. ${ }^{33}$ The observations that ET alone, ${ }^{28}$ or in combination with $\mathrm{CR}$, is associated with an increased protein expression of eNOS are of interest. Since eNOS is a component of the OT system as well as a downstream gene product of GATA $4,{ }^{26}$ it is possible that other transcription factors are involved in the synthesis of OT, NPs, and eNOS. In fact, GATA6 not only exerts overlapping functional redundancy with GATA4 in the regulation of these peptides but also is a direct transcriptional regulator of eNOS..$^{40,47}$ Endothelial GATA6 deficiency leads to decreased synthesis of eNOS, increased vascular injury, and worsened remodeling in the hypoxia- and monocrotaline-induced models of pulmonary hypertension. ${ }^{47}$ 
While treadmill running has positive gains on metabolic risk factors and vascular function in the $\mathrm{db} / \mathrm{db}$ mouse, ${ }^{35,36}$ this form of exercise is known to induce hyperglycemia by disrupting the hypothalamic-pituitary-adrenal axis, stimulate adrenal gland hypertrophy, and increase the secretion of catecholamines. ${ }^{39,48}$ We have demonstrated that $\mathrm{db} / \mathrm{db}$ mice remain hyperglycemic after forced treadmill exercise, a response caused by excessive corticosterone and catecholamine production. ${ }^{34}$ Excessive norepinephrine secretion during acute exercise is reported in hypertensive and nonhypertensive type 2 diabetic patients, and poor metabolic control is associated with postexercise hyperglycemia and hyperinsulinemia in patients with type 2 diabetes. ${ }^{49,50}$ Forced treadmill running increases the production of endogenous glucocorticoid and the expression of glucocorticoid receptor and gluconeogenic enzymes in liver from $\mathrm{db} / \mathrm{db}$ mice, leading to increased hepatic glucose production..$^{48}$ In addition, 11ß-hydroxysteroid dehydrogenase type 1 , which converts inactive cortisone to physiologically active corticosterone, is abundantly expressed in liver from $\mathrm{db} / \mathrm{db}$ mice after acute exercise, contributing to an increased glucocorticoid plasma pool and insulin resistance and further explaining the hyperglycemia noted in the $\mathrm{db} / \mathrm{db}$ mouse after training. ${ }^{34,48,51}$ Despite these changes with treadmill exercise, alternating moderate-intensity exercise with high-intensity exercise in each exercise session affords cardioprotection in the $\mathrm{db} / \mathrm{db}$ mouse but fails to improve the hyperglycemia and hyperinsulinemia. ${ }^{52}$ On the other hand, the metabolic disturbances linked to treadmill running are largely mitigated by voluntary wheel running exercise, supporting the use of voluntary exercise as a more physiologically gentle approach to reach desirable outcomes. ${ }^{34,51}$ Taken together, our results show that forced treadmill exercise may not always produce desirable effects with concurrent CR. The benefits of combining exercise with CR on metabolic control are better manifested with voluntary ET, as recently reported. Improved insulin sensitivity, increased neural function and synaptic plasticity, and reversal of mitochondrial dysfunction and oxidative stress have been reported in the $\mathrm{db} / \mathrm{db}$ mouse and under high-fat diet conditions. ${ }^{21,24,25}$ In these studies, one could also argue that the beneficial effects are attributed to a more restricted diet with decreases in caloric intake by $35-40 \%,{ }^{21,25}$ and by $50 \%,{ }^{21}$ resulting in a normalized mitochondrial function. Hence, increasing the exercise intensity by forced means does not always correlate with better metabolic control in the $\mathrm{db} / \mathrm{db}$ mouse compared to low-intensity voluntary wheel running and using voluntary running as an exercise paradigm, while subjecting mice to a more restricted caloric intake provides greater protection against the sequelae associated with diabetes.

Inactivity and excessive food consumption contribute to the development of obesity and diabetes. Diabetes induces cardiomyopathy, and evidence indicates that this is explained by defective synthesis of the cardiac OT-NP system. ${ }^{28}$ Here, we demonstrate that exercise in the form of forced moderateintensity ET with moderate $\mathrm{CR}$ does not significantly reverse the defect in the cardioprotective OT-NP-NO system in the db/ $\mathrm{db}$ mouse. However, we found that exercise and $\mathrm{CR}$ improved eNOS, suggesting that some protection is afforded by this strategy. The consequences of this disrupted system in the diabetic heart have been reported, including apoptosis, collagen accumulation in fibroblasts, lipid accumulation, decreased glucose uptake, and cardiomyocyte hypertrophy, ${ }^{26,29,53-55}$ and low plasma OT, ANP, and BNP are linked to increased sympathetic tone, impaired diuresis, increased volume, and reduced glucose utilization in the obese patient. ${ }^{56,57}$ Based on the significance of the cardiac OT system on cardiac function and metabolism, and that cardiovascular diseases account for $\sim 70 \%$ of diabetesrelated deaths, further studies are needed to develop strategies for the treatment of diabetes and obesity, as well as in patients with leptin deficiency or resistance. ${ }^{43}$

\section{Conclusion}

We show a mild effect of ET in combination with CR on cardioprotection in the $\mathrm{db} / \mathrm{db}$ mouse. Therefore, the development of exercise techniques and novel nutritional therapies to stimulate pathways that are different from those induced by diabetes and leptin resistance is essential for cardiometabolic health.

\section{Acknowledgments}

The study was funded by a grant from the Diabetes Action Research and Education Foundation (TLB), the Midwestern University Office of Research and Sponsored Programs (TLB), and the Canadian Institute for Health Research (JG and MJ).

\section{Disclosure}

The authors report no conflicts of interest in the work.

\section{References}

1. van der Berg JD, Stehouwer CD, Bosma H, et al. Associations of total amount and patterns of sedentary behaviour with type 2 diabetes and the metabolic syndrome: The Maastricht Study. Diabetologia. 2016; 59(4):709-718.

2. Tuomilehto J, Lindstrom J, Eriksson JG, et al. Prevention of type 2 diabetes mellitus by changes in lifestyle among subjects with impaired glucose tolerance. $N$ Engl J Med. 2001;344(18):1343-1350. 
3. Ravona-Springer R, Schnaider-Beeri M. The association of diabetes and dementia and possible implications for nondiabetic populations. Expert Rev Neurother. 2011;11(11):1609-1617.

4. Després JP. Physical activity, sedentary behaviours, and cardiovascular health: when will cardiorespiratory fitness become a vital sign? Can J Cardiol. 2016;32(4):505-513.

5. Boule NG, Haddad E, Kenny GP, Wells GA, Sigal RJ. Effects of exercise on glycemic control and body mass in type 2 diabetes mellitus: a meta-analysis of controlled clinical trials. JAMA. 2011;286(10): 1218-1227.

6. Diabetes Prevention Program Research Group. Reduction of the incidence of type 2 diabetes with lifestyle intervention or metformin. N Engl J Med. 2002;346:393-403.

7. Kelley DE, Goodpaster BH. Effects of exercise on glucose homeostasis in Type 2 diabetes mellitus. Med Sci Sports Exerc. 2001;33(6 Suppl): S495-S501.

8. Bajpeyi S, Pasarica M, Moro C, et al. Skeletal muscle mitochondrial capacity and insulin resistance in type 2 diabetes. $J$ Clin Endocrinol Metab. 2011;96(4):1160-1168.

9. Yokota T, Kinugawa S, Okita K, et al. Lower aerobic capacity was associated with abnormal intramuscular energetics in patients with metabolic syndrome. Hypertens Res. 2011;34(9):1029-1034.

10. Watson N, Dyer K, Buckley J, et al. Effects of low-fat diets differing in protein and carbohydrate content on cardiometabolic risk factors during weight loss and weight maintenance in obese adults with type 2 diabetes. Nutrients. 2016;8(5):E289.

11. Wing RR, Lang W, Wadden TA, et al. Benefits of modest weight loss in improving cardiovascular risk factors in overweight and obese individuals with type 2 diabetes. Diabetes Care. 2011;34(7):1481-1486.

12. Sohal RS, Weindruch R. Oxidative stress, caloric restriction, and aging. Science. 1996;273(5271):59-63

13. Noyan H, El-Mounayri O, Isserlin R, et al. Cardioprotective signature of short-term caloric restriction. PLoS One. 2015;10(6):e0130658.

14. Klebanov S, Herlihy JT, Freeman GL. Effect of long-term food restriction on cardiac mechanics. Am J Physiol. 1997;273(5 pt 2): H2333-H2342.

15. Broderick TL, Driedzic WR, Gillis M, Jacob J, Belke T. Effects of chronic food restriction and exercise training on the recovery of cardiac function following ischemia. J Gerontol A Biol Sci Med Sci. 2001; 56(1):B33-B37.

16. Heilbronn LK, de Jonge L, Frisard MI, et al. Effect of 6-month calorie restriction on biomarkers of longevity, metabolic adaptation, and oxidative stress in overweight individuals: a randomized controlled trial. JAMA. 2006;295(13):1539-1548.

17. Kanda Y, Hashiramoto M, Shimoda M, et al. Dietary restriction preserves the mass and function of pancreatic $\beta$ cells via cell kinetic regulation and suppression of oxidative/ER stress in diabetic mice. $J$ Nutr Biochem. 2015;26(3):219-226.

18. Kim KE, Jung Y, Min S, et al. Caloric restriction of $\mathrm{db} / \mathrm{db}$ mice reverts hepatic steatosis and body weight with divergent hepatic metabolism. Sci Rep. 2016;6:30111.

19. Schroeder M, Moran TH, Weller A. Attenuation of obesity by early-life food restriction in genetically hyperphagic male OLETF rats: peripheral mechanisms. Horm Behav. 2010;57(4-5):455-462.

20. Slentz CA, Bateman LA, Willis LH, et al. Effects of exercise training alone vs a combined exercise and nutritional lifestyle intervention on glucose homeostasis in prediabetic individuals: a randomised controlled trial. Diabetologia. 2016;59(10):2088-2098.

21. Suga T, Kinugawa S, Takada S, et al. Combination of exercise training and diet restriction normalizes limited exercise capacity and impaired skeletal muscle function in diet-induced diabetic mice. Endocrinology. 2014;155(1):68-80.

22. Cui M, Yu H, Wang J, Gao J, Li J. Chronic caloric restriction and exercise improve metabolic conditions of dietary-induced obese mice in autophagy correlated manner without involving AMPK. J Diabetes Res. 2013;2013:852754.
23. Marchianti AC, Arimura E, Ushikai M, Horiuchi M. Voluntary exercise under a food restriction condition decreases blood branched-chain amino acid levels, in addition to improvement of glucose and lipid metabolism, in $\mathrm{db}$ mice, animal model of type 2 diabetes. Environ Health Prev Med. 2014;19(5):339-347.

24. Dubuc PU, Cahn PJ, Willis P. The effects of exercise and food restriction on obesity and diabetes in young ob/ob mice. Int J Obes. 1984; $8(3): 271-278$.

25. Stranahan AM, Lee K, Martin B, et al. Voluntary exercise and caloric restriction enhance hippocampal dendritic spine density and BDNF levels in diabetic mice. Hippocampus. 2009;19(10):951-961.

26. Gutkowska J, Jankowski M, Mukaddam-Daher S, McCann SM. Oxytocin is a cardiovascular hormone. Braz JMed Biol Res. 2000;33:625-633.

27. Woods RL. Cardioprotective functions of atrial natriuretic peptide and B-type natriuretic peptide: a brief review. Clin Exp Pharmacol Physiol. 2004;31(11):791-794.

28. Gutkowska J, Broderick TL, Bogdan D, Wang D, Lavoie JM, Jankowski M. Downregulation of oxytocin and natriuretic peptides in diabetes: possible implications in cardiomyopathy. J Physiol. 2009;587(pt 19): 4725-4736.

29. Bartells ED, Nielson JM, Bisgaard LS, Goetze JP, Nielsen ED. Decreased expression of natriuretic peptides associated with lipid accumulation in cardiac ventricle of obese mice. Endocrinology. 2010; 151(11):5218-5225

30. Plante E, Menaouar A, Danalache BA, Broderick TL, Jankowski M, Gutkowska J. Treatment with brain natriuretic peptide prevents the development of cardiac dysfunction in obese diabetic $\mathrm{db} / \mathrm{db}$ mice. Diabetologia. 2014;57(6):1257-1267.

31. Plante E, Menaouar A, Danalache BA, et al. Oxytocin treatment prevents the cardiomyopathy observed in obese diabetic male $\mathrm{db} / \mathrm{db}$ mice. Endocrinology. 2015;156(4):1416-1428.

32. Gutkowska J, Paquette A, Wang D, Lavoie JM, Jankowski M. Effect of exercise training on cardiac oxytocin and natriuretic peptide systems in ovariectomized rats. Am J Physiol Regul Integr Comp Physiol. 2007;293(1):R267-R275.

33. Broderick TL, Parrott CR, Wang D, Jankowski M, Gutkowska J. Expression of GATA4 and downstream genes after exercise training in the $\mathrm{db} /$ db mouse. Pathophysiology. 2012;19:193-203.

34. Parrott CR, Ghosh P, Tedeschi J, Gunasekara G, Broderick TL. Urinary corticosterone and normetanephrine levels after voluntary and forced treadmill running in the $\mathrm{db} / \mathrm{db}$ mouse. J Diab Mell. 2011;40:71-78.

35. Esser KA, Su W, Matveev S, et al. Voluntary wheel running ameliorates vascular smooth muscle hyper-contractility in type 2 diabetic $\mathrm{db} / \mathrm{db}$ mice. Appl Physiol Nutr Metab. 2007;32(4):711-720.

36. Moien AF, Khazaei M, Ghosh S, et al. Exercise restores coronary vascular function independent of myogenic tone or hyperglycemic status in $\mathrm{db} /$ db mice. Am J Physiol Heart Circ Physiol. 2008;295(4):H1470-H1480.

37. Barouch LA, Berkowitz DE, Harrison RW, O’Donnell CP, Hare JM Disruption of leptin signaling contributes to cardiac hypertrophy independently of body weight in mice. Circulation. 2003;108(6):754-759.

38. Høydal MA, Wisløff U, Kemi OJ, Ellingsen O. Running speed and maximal oxygen uptake in rats and mice: practical implications for exercise training. Eur J Cardiovasc Prev Rehabil. 2007;14(6):753-760.

39. Molkentin JD. The zinc finger-containing transcription factors GATA$4,-5$, and -6 . Ubiquitously expressed regulators of tissue-specific gene expression. J Biol Chem. 2000;275:38949-38952.

40. Temsah R, Nemer M. GATA factors and transcriptional regulation of cardiac natriuretic peptide genes. Regul Pept. 2005;128(3):177-185.

41. Broderick TL, Jankowski M, Wang D, Danalache BA, Parrott CR, Gutkowska J. Downregulation in GATA4 and downstream structural and contractile genes in the $\mathrm{db} / \mathrm{db}$ mouse heart. ISRN Endocrinol. 2012;2012:736860.

42. Jordens I, Molle D, Xiong W, Keller SR, McGraw TE. Insulin-regulated aminopeptidase is a key regulator of GLUT4 trafficking by controlling the sorting of GLUT4 from endosomes to specialized insulin-regulated vesicles. Mol Biol Cell. 2010;21(12):2034-2044. 
43. Farr OM, Gavrieli A, Mantzoros CS. Leptin applications in 2015: what have we learned about leptin and obesity? Curr Opin Endocrinol Diabetes Obes. 2015;22(5):353-359.

44. Kobayashi S, Mao K, Zheng H, et al. Diminished GATA4 protein levels contribute to hyperglycemia-induced cardiomyocyte injury. J Biol Chem. 2007;282(30):21945-21952.

45. Belke DD, Larsen TS, Gibbs EM, Severson DL. Altered metabolism causes cardiac dysfunction in perfused hearts from diabetic $(\mathrm{db} / \mathrm{db})$ mice. Am J Physiol Endocrinol Metab. 2000;279(5):E1104-E1113.

46. Broderick TL, Wang D, Jankowski M, Gutkowska J. Unexpected effects of voluntary exercise training on natriuretic peptide and receptor mRNA expression in the ob/ob mouse heart. Regul Pept. 2014;188: 52-59.

47. Ghatnekar A, Chrobak I, Reese C, et al. Endothelial GATA-6 deficiency promotes pulmonary arterial hypertension. Am J Pathol. 2013; 182(6):2391-2406.

48. Brust KB, Corbell KA, Al-Nakkash L, Babu JR, Broderick TL. Expression of gluconeogenic enzymes and $11 \beta$-hydroxysteroid dehydrogenase type 1 in liver of diabetic mice after acute exercise. Diabetes Metab Syndr Obes. 2014;7:495-504.

49. Kjaer M, Hollenbeck CB, Frey-Hewitt B, Galbo H, Haskell W, Reaven GM. Glucoregulation and hormonal responses to maximal exercise in non-insulin-dependent diabetes. J Appl Physiol. 1990;68(5): 2067-2074.
50. Hubinger A, Franzen A, Gries FA. Hormonal and metabolic response to physical exercise in hyperinsulinemic and non-hyperinsulinemic type 2 diabetics. Diabetes Res. 1987;4(2):57-61.

51. Sennott J, Morrissey J, Standley PR, Broderick TL. Treadmill exercise fails to reverse defects in glucose, insulin and muscle GLUT4 content in the $\mathrm{db} / \mathrm{db}$ mouse model of diabetes. Pathophysiology. 2008;15:173-179.

52. Stølen TO, Høydal MA, Kemi OJ, et al. Interval training normalizes cardiomyocyte function, diastolic $\mathrm{Ca} 2+$ control, and $\mathrm{SR} \mathrm{Ca} 2+$ release synchronicity in a mouse model of diabetic cardiomyopathy. Circ Res. 2009;105(6):527-536.

53. Florian M, Jankowski M, Gutkowska J. Oxytocin increases glucose uptake in neonatal cardiomyocytes. Endocrinology. 2010;151:482-491.

54. Mascareno E, Beckles D, Dhar-Mascareno M, Siddiqui MAQ. Enhanced hypertrophy in ob/ob mice due to impairment in expression of atrial natriuretic peptide. Vascul Pharmacol. 2009;51:198-204.

55. Kuhn M. Molecular physiology of natriuretic peptide signalling. Basic Res Cardiol. 2004;99(2):76-82.

56. Qian W, Zhu T, Tang B, et al. Decreased circulating levels of oxytocin in obesity and newly diagnosed type 2 diabetic patients. J Clin Endocrinol Metab. 2014;99(12):4683-4689.

57. Taylor JA, Christenson RH, Rao K, Jorge M, Gottlieb SS. B-type natriuretic peptide and $\mathrm{N}$-terminal pro B-type natriuretic peptide are depressed in obesity despite higher left ventricular end diastolic pressures. Am Heart J. 2006;152:1071-1076.
Diabetes, Metabolic Syndrome and Obesity: Targets and Therapy is an international, peer-reviewed open-access journal committed to the rapid publication of the latest laboratory and clinical findings in the fields of diabetes, metabolic syndrome and obesity research. Original research, review, case reports, hypothesis formation, expert opinion and commentaries are all considered for publication. The manuscript management system is completely online and includes a very quick and fair peer-review system, which is all easy to use. Visit http://www.dovepress.com/testimonials.php to read real quotes from published authors. 